\title{
Research on Talent Training Mode of "Iron Man" Craftsman under Modern Apprenticeship System
}

\author{
Ren Ning \\ Heilongjiang Daqing Vocational College, Heilongjiang, China, 163411
}

Keywords: modern apprenticeship, colleges, iron man, training mode

Abstract: With the increasing number of students in China's colleges and universities in recent years, the ability and quality of students trained by different professions has become an important indicator for enterprises to choose talents. Therefore, how to further enhance and cultivate the overall ability and learning direction of students in colleges and universities is also a topic actively explored by many scholars in China's colleges and universities. The author has a certain view on the development and cultivation of students through the practical teaching and understanding of modern apprenticeship in colleges and universities, and actively discusses the dilemma and countermeasures in the construction of the "iron man" course system in the apprenticeship pilot program. Exploring and cultivating students has made the apprenticeship pilot work more complete.

\section{Introduction}

The so-called "iron man" training mode under the modern apprenticeship system refers to the active cooperation mechanism between the institutions and the off-campus related enterprises, so that the development and cultivation of talents can be carried out in a more in-depth manner, and the quality of teaching can be actively improved. As a student recruited by the company, it must have a high level of competence and quality, and its service awareness must be very clear. However, in the current view, most of the students in colleges and universities in China are more unique or eloquent, self-contained, and have a very shallow sense of collective behavior. These students also show the characteristics of poor responsibility and natural ability to do things. And quality needs to be improved ${ }^{[1]}$. At present, China is at a stage of rapid economic development. Therefore, how to cultivate students' excellent ability and the overall quality of students is a problem that all major institutions need to explore. The main reason for rethinking the problems in the implementation of the modern apprenticeship pilot program is that the operational mechanism is not comprehensive enough $^{[2]}$.

\section{The connotation and basic characteristics of modern apprenticeship}

\subsection{The connotation of modern apprenticeship}

The so-called apprenticeship system refers to the mechanism of the colleges and universities actively cooperating with relevant enterprises outside the school. It is more straightforward to say 
that in actual production, the masters and students are taught by the students, and the disciples listen carefully to learn together to create the development needs of the enterprise. Professional talents, as shown in Figure 1 below, are the training trends of the "iron man" craftsman talents under the modern apprenticeship system:

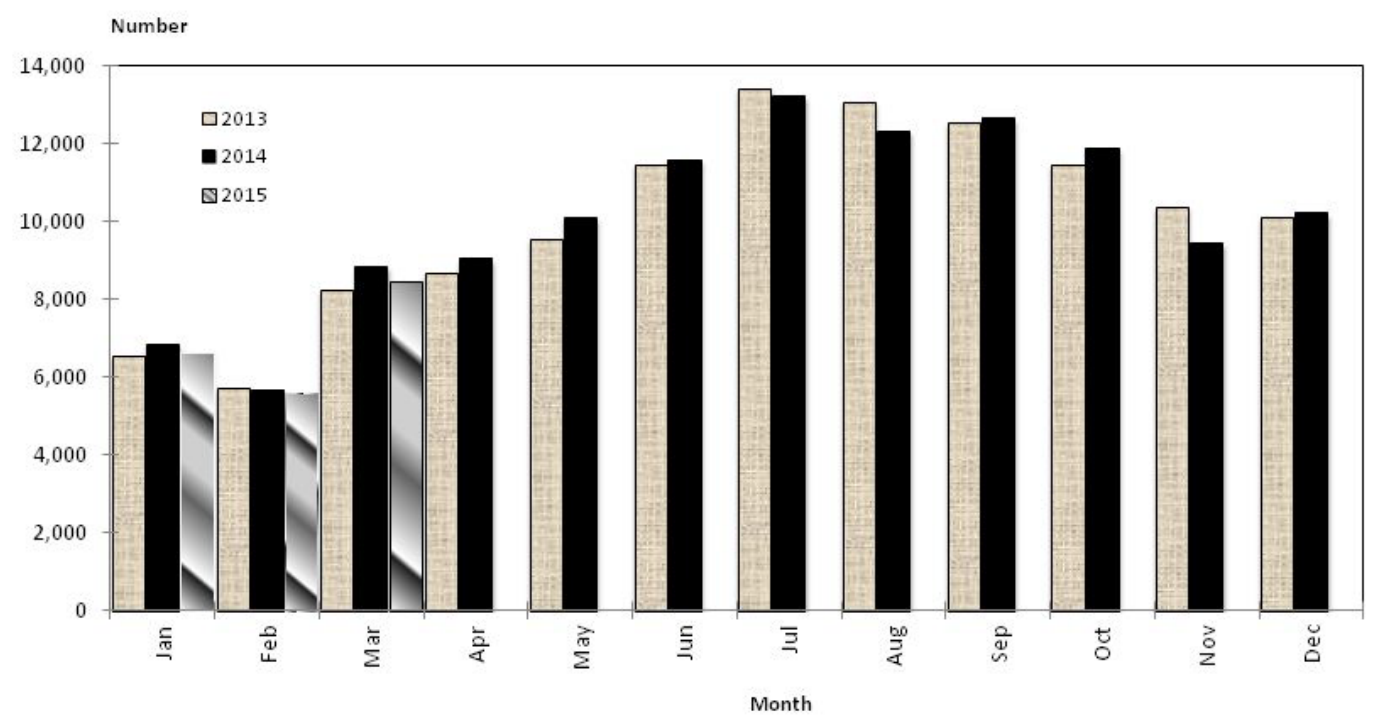

Figure 1: Trends in the cultivation of "iron man" craftsmen under the modern apprenticeship ${ }^{\text {[1] }}$

According to the sequence of time development shown in Figure 1, China is currently in the midst of a historical transition from an economically developing medium-sized country to an economic powerhouse ${ }^{[2]}$. With the continuous development of China's various corporate undertakings, the industry's demand for professional talents. It also began to get very big. The company pays more attention to the ability of students and the sense of service. These aspects can also be perfected and compensated by the modern apprenticeship system. Therefore, the strategy of modern apprenticeship training for professional students is still very important.

\subsection{The basic characteristics of modern apprenticeship}

As a newly introduced talent training model in China, this system has the following obvious characteristics:

\subsection{1 "Double Identity" of Modern Apprenticeship}

The term "dual identity" as used herein refers to the identity of students, on the one hand, students on campus; on the other hand, they have become apprentices in enterprises, and mainly based on students. By cultivating the quality of students of different majors, colleges and universities have certain requirements and training for the professional quality of students. In the enterprise, it is more necessary to cultivate students' certain professional qualities ${ }^{[3]}$.

This also requires the colleges to pay more attention to cultivating students with post-service awareness, and has higher requirements for students' comprehensive professional service ability and ability to adapt to the situation. On the other hand, students who are "apprentices" of enterprises can master the essence of work in real daily work, and under the educational characteristics of colleges and universities, they must propose a series of quality training suggestions for modern apprentice students. The development of institutions and surrounding enterprises has a positive impact and lays the foundation for subsequent work. 


\subsection{2 "Diversified Education Program" for Modern Apprenticeship}

As an important training and development platform for a large number of professionals, institutions have the ability to influence the quality of students' future development. The teaching quality and teaching effect of different majors in colleges and universities can directly affect the professional quality of students, which is also very influential for the long-term development of students. Therefore, under the background of the new era, colleges and universities should increase the cultivation of students' "diversified" professional quality, and build the "diversified education program" shown in Figure 2 below to improve students' professional quality and ability ${ }^{[4]}$. Have a certain deepening training:

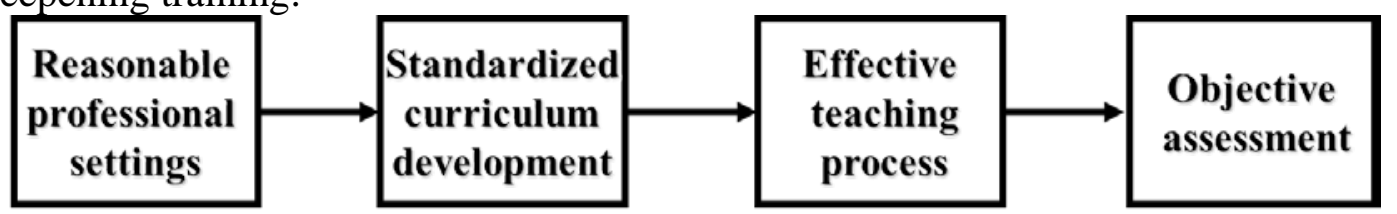

Figure 2: "Diversified Education Program” under the Modern Apprenticeship System

As shown in Figure 2 above, the "diversified education program”, diversified ability and special skills are one of the important foundations for students to adapt to future development needs, and according to the current requirements of relevant quality standards in China, Teaching ${ }^{[3]}$.

In combination with the actual development of the school, students can develop autonomous comprehensive learning and practical ability training, so that students can become qualified enterprise technicians after the modern apprenticeship transformation. The author also provides certain guidance for the teaching of students in colleges and universities by studying the development trend of the "diversification" of modern apprenticeship.

\section{3 "Activity Management Program" for Modern Apprenticeship}

It is very important for the future development of students in colleges and universities to meet the needs of enterprises. The "activity management program" of modern apprenticeship is mainly divided into the following aspects: firstly, the improvement of ideological image, followed by the development of professional knowledge. In the process of "task-based" teaching in colleges and universities, students should be combined with the current practical ability to innovate and reform students' development, so as to truly play the role of higher vocational education and create excellent conditions for students' future work. . In terms of the overall quality of students in colleges and universities in China, the modern apprenticeship system promotes students' ability to improve their own ability has become a very important research topic, and in this context, only through the in-depth analysis of students' abilities and dilemmas, put forward development suggestions and do a long-term improvement for students ${ }^{[3]}$.

\section{4 "Adaptability Enhancement Ability" of Modern Apprenticeship}

For students in the institution, the internal activities of the school are very common for students. Guiding and developing the overall quality of students and encouraging students to participate in campus cultural activities play an important role in the positive development of students. And these skills are constantly improving in the school, and can also show their excellent side when they are "apprentices" of the company. And by establishing relevant associations, a culture of learning and development is built within the school. This "elastic improvement" is mainly formed by the framework structure shown in Figure 3 below: 


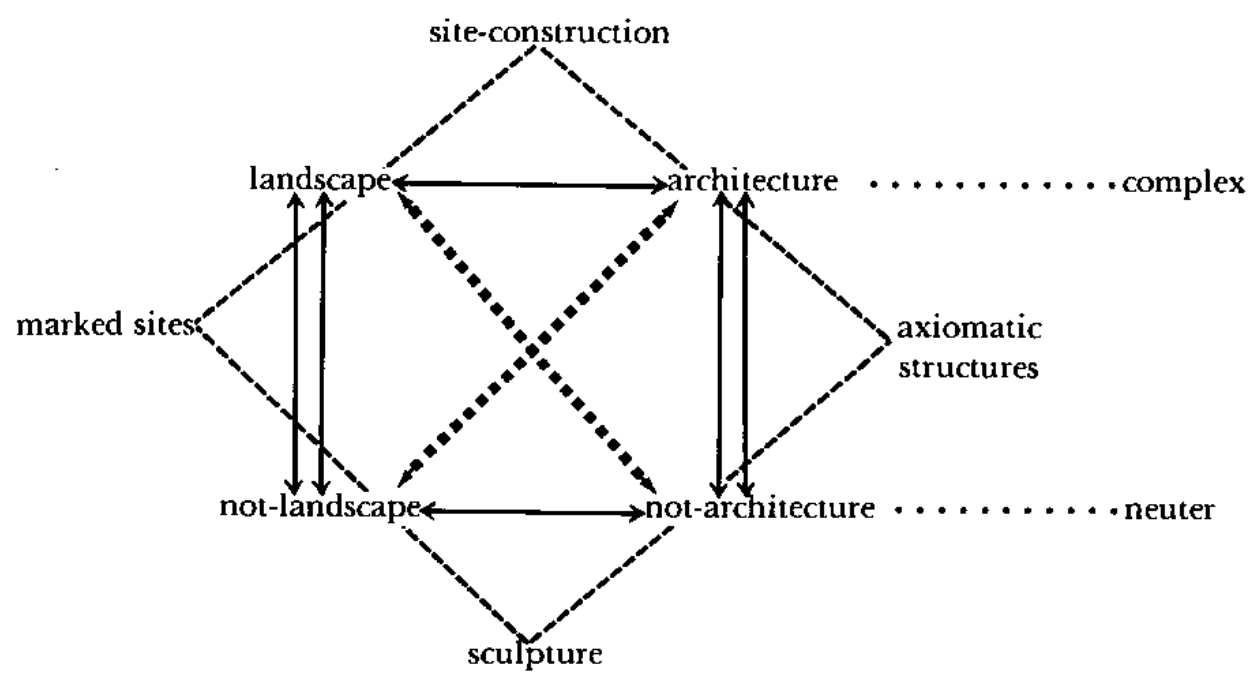

Figure 3: "Evaluation of Elasticity” of Modern Apprenticeship

As shown in Figure 3 above, it is also possible to hold a number of competitions or professional quality related competitions within the school, and to allow students to develop in a comprehensive manner through different competition forms. In addition, for the activities outside the school, by organizing students to participate in some large-scale activities, the overall quality of the students can be improved. As an "apprentice", you can also participate in corporate activities in a company that works, and in the real world, it can also improve the overall ability of the "apprentice" "4].

\section{The dilemma of the modern apprenticeship pilot}

In the process of the modern apprenticeship pilot program, the fundamental dilemma that emerged, as mentioned above, is that the apprenticeship mechanism is still not perfect. This will lead to friction in all aspects of the modern apprenticeship. The lack of perfection of this operating mechanism is also reflected in the following aspects:

- The overall age structure is also uneven;

- The situation of complementary advantages is limited;

- The enthusiasm of enterprises to participate has gradually failed.

- The development and cooperation between schools and enterprises is not deep enough;

- The understanding of the mechanism of apprenticeship in business managers is not clear enough;

- The overall situation of mutual benefit between schools and enterprises is limited;

The modern apprenticeship system is an emerging model for cultivating talents. This model allows talents to have more foundations to develop their abilities based on the relevant participation of employers, and gradually realize targeted training of talents. This is true for real enterprises ${ }^{[2]}$. The professional environment is very helpful, and it is also the key to the company's own development of its human resources and technical services. By mobilizing the enthusiasm of the participating talents in the industry, it is possible to effectively promote cooperation between the campus and the enterprise, making resource sharing and information exchanges an easy task. In order to solve the current predicament, its most basic advantage lies in the establishment of a safeguard mechanism for safeguarding the enterprise, and the mutual benefit of various aspects through the basis of complementary advantages, so as to solve the different dilemmas caused by the problem of the operational mechanism ${ }^{[3]}$. 


\section{Conclusions}

The so-called modern apprenticeship pilot program refers to the active cooperation mechanism between the institutions and the off-campus related enterprises, so that the development and cultivation of talents can be carried out in a more in-depth manner, and the quality of teaching can be actively improved. At present, China is at a stage of rapid economic development. Therefore, how to cultivate students' excellent ability and the overall quality of students is a problem that all major institutions need to explore. The modern apprenticeship system is an emerging model for cultivating talents. This model allows talents to have more foundations to develop their abilities based on the relevant participation of employers, and gradually realize targeted training of talents. This is true for real enterprises. The professional environment is very helpful. Therefore, in this context, it is necessary to create an "iron man" craftsman talent training model, put forward development proposals and make long-term improvement for students.

\section{Acknowledgement}

Research on the Training Model of "Iron Man" Craftsman Talents under the Modern Apprenticeship System (Project No. GZE1317004)

\section{References}

[1] Juyan L I, Zheng G. Cultivation of the "Craftsman Spirit" in the Agricultural Vocational Education and the Modern Apprenticeship System[J]. Heilongjiang Agricultural Sciences, 2018.

[2] Buser T, Peter N, Wolter S C. Gender, Willingness to Compete and Career Choices Along the Whole Ability Distribution[J]. Iza Discussion Papers, 2017.

[3] Levers S W. From Revelation to Dilation in Dante's Studio[J]. Dante Studies, 2016, 134.

[4] Ryley M. The UK apprenticeship levy: What you need to know[J]. Renewable Energy Focus, 2016, 17(4):132-133. 